\title{
Phage Endolysins as Potential Antimicrobials against Multidrug Resistant Vibrio alginolyticus and Vibrio parahaemolyticus: Current Status of Research and Challenges Ahead
}

\author{
Nandita Matamp and Sarita G. Bhat * \\ Department of Biotechnology, Cochin University of Science and Technology, Kochi-682022, Kerala, India; \\ nandita.matamp@gmail.com \\ * Correspondence: saritagbhat@gmail.com; Tel.: 91-984-603-3486. Fax: 0484-257-7595
}

Received: 25 February 2019; Accepted: 15 March 2019; Published: 18 March 2019

\begin{abstract}
Vibrio alginolyticus and V. parahaemolyticus, the causative agents of Vibriosis in marine vertebrates and invertebrates, are also responsible for fatal illnesses such as gastroenteritis, septicemia, and necrotizing fasciitis in humans via the ingestion of contaminated seafood. Aquaculture farmers often rely on extensive prophylactic use of antibiotics in farmed fish to mitigate Vibrios and their biofilms. This has been postulated as being of serious concern in the escalation of antibiotic resistant Vibrios. For this reason, alternative strategies to combat aquaculture pathogens are in high demand. Bacteriophage-derived lytic enzymes and proteins are of interest to the scientific community as promising tools with which to diminish our dependency on antibiotics. Lysqdvp001 is the best-characterized endolysin with lytic activity against multiple species of Vibrios. Various homologues of Vibrio phage endolysins have also been studied for their antibacterial potential. These novel endolysins are the major focus of this mini review.
\end{abstract}

Keywords: antibiotic resistance; endolysin; Vibrio alginolyticus; V. parahaemolyticus

\section{Introduction}

Vibrio alginolyticus and V. parahaemolyticus, the normal inhabitants of estuarine and marine environments, are notable human enteropathogens associated with seafood-borne mortality and illness worldwide. V. alginolyticus is reported as the etiological agent of wound and ear infections (both otitis media and otitis externa), intracranial infection, peritonitis and osteomyelitis among many others [1-3], while V. parahaemolyticus causes bacterial gastroenteritis associated with the consumption of raw or undercooked seafood $[4,5]$.

In aquaculture, the hazard of infectious diseases has led to significant stock losses and problems with animal welfare. Hence, intensive aquaculture promotes the indiscriminate use of anti-microbials, thereby causing the dissemination of antimicrobial-resistant (AMR) bacteria and resistance genes in aquaculture products and the environment [6]. This global concern has necessitated the exploration of alternative therapies for bacterial pathogens in animal production, especially in aquaculture. Amongst the several substitutes, that include probiotics, essential oils and anti-microbial peptides, phage therapy has gained much attention for preventing and controlling pathogenic infections in aquaculture facilities. Recent advances in phage genome sequencing have kindled the application of phage encoded enzymes, especially endolysins, as biocontrol and therapeutic agents against major food-borne pathogens.

There have been numerous reviews on endolysins as antimicrobials against Gram-positive bacteria. However, in this review, we concentrate on phage lysin biology against Gram-negative pathogens $V$. alginolyticus and $V$. parahaemolyticus. The endolysin characteristics that are important to combatting 
multidrug resistant Vibrios are summarized, thereby outlining the remarkable potency of these enzymes in the mitigation of similar pathogens in aquaculture.

\section{Antibiotic Resistance in Vibrios alginolyticus and V. parahaemolyticus}

Antimicrobial/chemotherapeutic agents against $V$. alginolyticus and $V$. parahaemolyticus are used either as feed additives and/or as immersion bath solutions in fish farms. The recommended antibiotics against Vibrios are fluoroquinolones (ciprofloxacin, levofloxacin), tetracyclines (doxycycline, tetracycline), third-generation cephalosporins (cefotaxime, ceftazidime, ceftriaxone), aminoglycosides (amikacin, apramycin, gentamicin, streptomycin) and folate pathway inhibitors (trimethoprim-sulfamethoxazole) [7]. The excessive use of antibiotics has led to the evolution of numerous strains that exhibit resistance to a single or a combination of antibiotics. However, as reported by the United States Centers for Disease Control and Prevention (CDC), the occurrence of Vibrio-related infections has increased dramatically since 2001 [8] (CDC, 2016).

Gram-negative bacteria have developed divergent mechanisms to bypass the inhibitory effects of antibiotics such as (1) drug inactivation/destruction (2) decreased antibiotic penetration and efflux (3) target site modification and (4) global cell adaptations [9-11]. Genes and associated insertion elements, which confer antibiotic resistance, are usually found localized in plasmids as multi-resistance regions (MRR) in these organisms [12]. Studies of antibiotic resistance in many pathogens such as $V$. cholera, Staphylococcus aureus and Salmonella have been reported, but the mechanism of the same in $V$. alginolyticus and $V$. parahaemolyticus is poorly documented [13].

Fluoroquinolones, a promising class of broad-spectrum antibiotics, are direct inhibitors of DNA synthesis. They bind to the enzyme-DNA complex and stabilize DNA strand breaks created by the enzymes DNA gyrase and topoisomerase IV. [14]. Kitaoka and his co-workers have reported the presence of spontaneous chromosomal mutations in gyrA and parC genes in Vibrios that encode subunits of DNA gyrase and topoisomerase IV, respectively. These mutations could alter the affinity of theses enzymes, thus protecting Vibrios from quinolones. [15]. Self-transmissible plasmids that confer resistance by plasmid-mediated quinolone resistance (PMQR) mechanisms were also being investigated in $V$. parahaemolyticus [16]. Tetracycline has been recommended as the antimicrobial of choice for the treatment of severe Vibrio infections, thanks to its ability to inhibit the synthesis of pathogenic extracellular enzymes [17]. The emergence of $V$. alginolyticus possessing tet plasmids for tetracycline resistance [18] and pVAS3-1 plasmids for $\beta$-lactamase resistance is alarming [19].

\section{Treatment Costs for Vibriosis}

According to CDC Outbreak Surveillance Data, around 6680 cases of V. parahaemolyticus and 165 cases of $V$. alginolyticus have been reported annually. The annual health costs of Vibrio infections are estimated to be over $\$ 30$ million. These data are quite imprecise due to limitations of surveillance data and underreporting. Under such circumstances, the costs are likely higher, leading to considerable uncertainty into the overall estimate. In addition to the hike in treatment costs, antimicrobial resistance can lead to protracted hospital stays and escalations in morbidity and mortality rates [20].

\section{Bacteriophage Endolysins-'the Holy Grail' to Control Food Borne Pathogens}

Bacteriophages or phages are viruses that specifically infect and lyse bacteria. Following their discovery by Twort and Felix D'Herelle, it became clear that they exhibit two kinds of life cycles: lytic (used by both virulent and temperate phages) and lysogenic (used exclusively by temperate or pro-phages) [21]. Lytic or virulent phages have evolved a lytic system to weaken the bacterial cell wall, leading to bacterial lysis. This bacterial lysis is achieved by phage-encoded muralytic enzymes called Endolysins (or lysins) that degrade the peptidoglycan (PG) layer present in the bacterial cell wall during the final stage of the phage reproduction events. The lysis events of double-stranded DNA bacteriophages can be elucidated by three different mechanisms. The most explicitly demonstrated mechanism is canonical lysis, where lysins act on PG layer with the help of a second phage encoded 
protein called holin, in a timely-controlled fashion [22]. Holins depolarize the cytoplasmic membrane by allowing endolysins to diffuse through pores in the membrane and target the PG layer. The second pathway is mediated by a special class of holins designated as pinholins which forms small, heptametrical channels in the membrane instead of large holes as seen in canonical lytic pathway. These pinholins work in association with Signal-arrest-release (SAR) endolysins which are inactive tethered enzymes accumulated in the periplasm. Using proton motor force (PMF), pinholins trigger the activation of these pro-enzymes, refolding their configuration leading to their release from the bi-layer, thereby degrading PG. Pinholins act as timers for endolysin activation playing no lead role in their export. In Gram-negative hosts, the lysis of $\mathrm{OM}$ is by a third functional class of lysis proteins called the spanins [23]. Spanin complex consists of small outer membrane lipoprotein (o-spanin) and an integral cytoplasmic membrane protein (i-spanin) which disrupts OM by 3 modes: (i) enzymatic degradation of PG cross links [24] (ii) pore formation [25] and (iii) inner membrane-outer membrane fusion [26]. Phage researchers have termed these enzymes as 'enzybiotics'; they can be exploited for their ability to kill variety of pathogens [27].

\section{Gram-Negative Endolysins as Antimicrobials}

\section{Basic Structure and Function}

The peptidoglycan layer is the major structural component of the bacterial cell wall responsible for protection, physical integrity and shape. It is composed of chains of alternating residues of $\mathrm{N}$-acetylmuramic acid (MurNAc) and N-acetylglucosamine (GlcNAc), connected by $\beta-1,4$ glycosidic bonds, linked to a short stem of tetrapeptide [28]. The cell wall of Gram-negative organisms has an outer membrane (OM) situated above a thin PG layer and the limited permeability of OM [29] poses a major hurdle for development of novel antimicrobials against Gram-negative pathogens preventing many compounds from reaching their intracellular targets. Since the endolysin susceptible layer (PG) is found between an inner and outer membrane, effective strategies, like use of peptides, detergents, and chelators, should be applied in combination with hydrolytic enzymes to improve the applicability of phage lysins. As an example, $5 \mathrm{mM}$ EDTA used in combination with E. coli phage endolysin PlyE146 $400 \mu \mathrm{g} / \mathrm{mL}$, decreased titers of E. coli K12 by ca. $2 \log _{10}$ CFU/mL upon 2 hours of incubation. [30]. Moreover, the peptide moiety made of L- and D-amino acids is highly conserved (chemotype A1 $\gamma$ ) in Gram-negative organisms, whereas the carbohydrate backbone is conserved in both Gram-positive and negative bacteria.

Phage endolysins are analogous in structure and function to bacterial lysins, and are closely related to the small family of mammalian PG recognition proteins [31]. They can have either a globular or modular structure. Endolysins from phages infecting Gram-negative hosts are mostly small single-enzymatically active domain (EAD) globular proteins (molecular mass 15-20 kDa) without a specific cell wall binding domain (CBD) module [32,33]. An EAD cleaves a specific bond in the PG structure, whereas a CBD targets the EAD to its substrate by binding PG or another cell wall component. Apart from these two domains, recent reports of some Gram-negative antibacterial endolysins have revealed another domain CHAP (cysteine,histidine-dependent amidohydrolase/peptidase) belonging to amidase family whose role is to facilitate hydrolysis of the PG layer [34,35]. This feature enables them to enhance their catalytic skills by binding to multiple sites during cell lysis. An endolysin isolated from a phage infecting a Gram-negative species is therefore enzymatically-active on the PG of any other Gram-negative strain [36].

The first endolysins infecting Gram-negative bacteria were reported in the 1960s, and were mostly encoded by T-phages infecting Escherichia coli. Earlier, they were simply referred to as 'lysozymes' based on their functional similarity to egg white lysozyme, a muralytic enzyme well noted for its anti-bacterial activity. Later, based on the mechanism of action, PG hydrolases were classified into 4 groups: (a) glycosidases which cleave the glycan component of peptidoglycan, (b) amidohydrolase, that cleaves amide bond between the glycan moiety (MurNAc) and the peptide moiety (L-alanine) 
of the PG (c) endopeptidase which cleaves peptide bonds between two amino acids, and finally, (d) lytic transglycosylases that cleave the $\beta(1-4)$ linkages between NAM and NAG residues of the PG. Transglycosylases are not true hydrolases, as they do not require water to catalyze PG cleavage. Most of the endolysins reported so far are lytic transglycosylases. The complexity of endolysins can be further illustrated by the fact that an elaborate motif search of approximately 723 putative endolysins in database has revealed the presence of 24 types of catalytic domains, 13 binding domains, and 89 possible architectural organizations [37].

The modular structure of endolysin has facilitated development of engineered lysins with desired properties such as higher stability, solubility and broad killing spectrum. Because of the independent functions of N-terminal catalytic domain (CD) and a C-terminal cell-wall binding domain (CBD), lysins can be constructed by fusing them from different origins or with other molecules [38]. Among the engineered lysins, chimeolysins and artilysins are worth mentioning. Several chimeolysins have been constructed with extended broad spectrum activity against Gram-positive pathogens like Staphylococcus, Streptococci and E. faecalis [39-43]. Recently, novel chimeolysin (ClyF) active against planktonic and biofilm MRSA designed from a chimeolysin library with different combinations of CDs and CBDs was expressed in E. coli [44]. Artilysins are outer membrane-penetrating lysins constructed by fusing a fragment of natural lysin with peptides or other proteins with high anti-bacterial activity against Gram-negative pathogens. The lipopolysaccharide destabilizing peptides of artilysins can be effectively exploited against Pseudomonas, E. coli, Salmonella and Yersinia $[45,46]$. The concept of endolysin delivery against Gram-negatives is further expanded by the development of Innolysins which are constructed by combining receptor binding proteins (RBPs) of candidate phages. Zampara and his co-workers constructed twelve Innolysins using phage T5 endolysin and receptor binding protein $\mathrm{Pb} 5$, which bind irreversibly to the phage receptor FhuA involved in ferrichrome transport in $E$ coli. It was proved that they pass through the outer membrane and degrade the PG layer, thereby killing the target bacteria [47].

\section{Vibrio Phage Endolysins}

Phage therapy experiments have shown promising results in the eradication of several pathogenic Vibrios (V. harveyi, V. parahaemolyticus, V. alginolyticus, V. splendidus, V. anguillarum, in aquaculture settings since 1999 [48-52]. The extensive amount of genetic information assembled from phage whole genome sequencing has opened up new horizons to design novel antimicrobial agents. In this respect, timely exploration into utilization of Vibrio phage endolysins has sparkled interest among active phage researchers. Table 1 shows the complete list (to date) of all endolysins/putative ORFs coded by $V$. alginolyticus and $V$. parahaemolyticus. The three dimensional structures of Vibrio phage endolysins have been predicted by homology modeling (Figure 1). 
Table 1. Showing endolysins of Vibrio alginolyticus and V. parahaemolyticus phages.

\begin{tabular}{|c|c|c|c|c|}
\hline Bacteria & Phage & $\begin{array}{c}\text { Putative } \\
\text { Endolysins/Predicted } \\
\text { Orfs }\end{array}$ & Features & Reference \\
\hline \multirow{7}{*}{ Vibrio alginolyticus } & PVA1 & gp60 & Putative lysozyme family protein * & [50] \\
\hline & phi-Grn1 & phiGrn1_0012 & SLT domain protein/endolysin * & [53] \\
\hline & ValKK3 & ORF304 & Tail lysozyme & [54] \\
\hline & Athena1 & Cds006 & Protein with lysozyme activity * & [55] \\
\hline & VEN & gp50 & Cell wall hydrolase-like protein * & [56] \\
\hline & Vp670 & cwlQ & endolysin & [57] \\
\hline & vB_ValP_IME271 & CDS64 & endolysin & [58] \\
\hline \multirow{6}{*}{ V. parahaemolyticus } & qdvp001 & Lysqdvp001 & modular endolysin & [59] \\
\hline & VP06 & PP_00050 & $\begin{array}{l}\text { membrane-bound lytic murein } \\
\text { transglycosylase * }\end{array}$ & [60] \\
\hline & VPp1 & LysVPp1 & endolysin & [61] \\
\hline & VPMS1 & LysVPMS1 & endolysin & [62] \\
\hline & VpKK5 & ORF62 & $\begin{array}{l}N \text {-acetylmuramoyl-L-alanine } \\
\text { amidase * }\end{array}$ & [63] \\
\hline & pTD1 & BAW98403.1 & Endolysin* & [64] \\
\hline
\end{tabular}

* indicates the newly identified features of sequenced endolysins as part of the present study.

PVA1

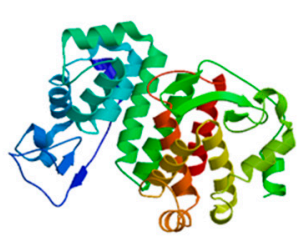

VEN

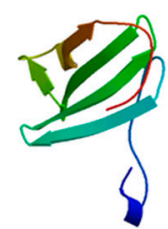

VP06

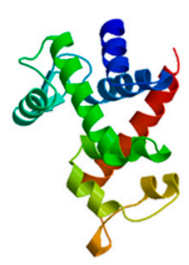

phi-Grn1

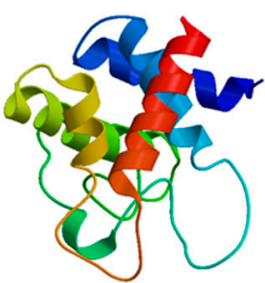

Vp670

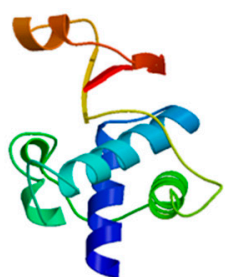

VPp1

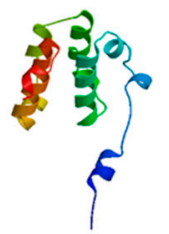

VALKK3

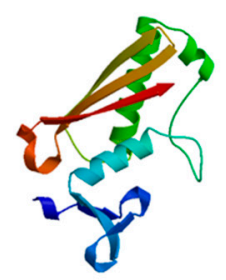

vB_ValP_IME271

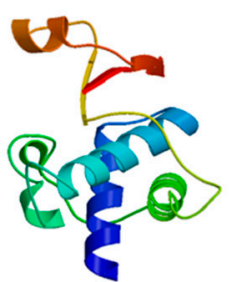

VPMS1

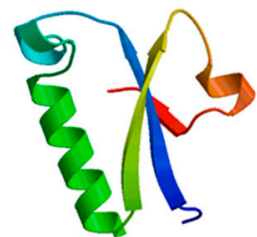

Athena1

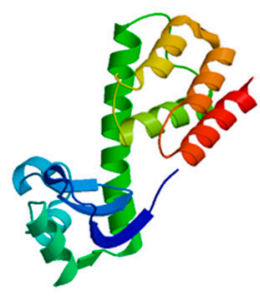

qdvp001

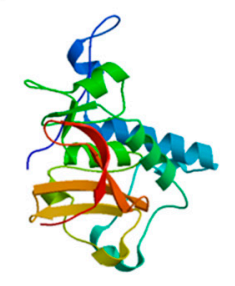

VpKK5

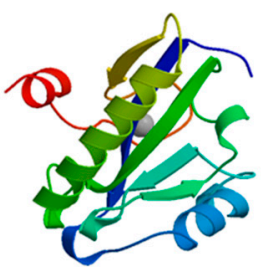

Figure 1. Structural modeling of Vibrio phage endolysins. 


\subsection{Lysqdop001 and Its Homologues}

\subsubsection{Structure, Function and Physiochemical Properties}

The endolysin Lysqdvp001 is derived from V. parahaemolyticus bacteriophage qdvp001, a lytic broad-spectrum phage belonging to Myoviridae family with genome length of 134,742-bp. [59]. The endolysin gene (ORF 60) of qdvp001 has a close relationship to Vibrio (cholerae) phage ICP1, which shares the same modular structure with ORF 60. The PG_binding _1 domain of the Vibrio phage ICP1 endolysin gene is $58 \%$ homologous to ORF 60 , whereas the CHAP domain shares a $66 \%$ amino acid sequence identity. Interestingly, SMART analysis of endolysin has shown an unusual structure with two domains: a PG binding (PF01471) domain and a CHAP (PF05257) domain. Lysins with dual domains have been mostly reported in phages infecting Gram-positive pathogens and rare among bacteriophages infecting Gram-negative bacteria [65]. Lysqdvp001 is a modular endolysin with no transmembrane regions or signal peptide regions. Bioinformatic analysis also revealed the absence of any holins to assist the function of Lysqdvp001. The estimated molecular weight is $25.9 \mathrm{kDa}$ and pI value is 5.97. The endolysin was cloned in competent E. coli BL21 Star ${ }^{\mathrm{TM}}$ (DE3) strain and the recombinant endolysin has a good yield of $10.4 \mathrm{~g}$ from $300 \mathrm{~mL}$ of E.coli culture. Turbidity reduction assay of the purified product demonstrated promising results as the endolysin reduced turbidity of host bacteria by $0.6 \mathrm{log}$ upon $5 \mathrm{~min}$ of incubation. This effective reduction was observed due to pretreatment of bacterial culture with EDTA for $5 \mathrm{~min}$. Furthermore, Lysqdvp001 was able to lyse $11 / 11$ V. parahaemolyticus strains tested, whereas the parent bacteriophage qdvp001 had a shorter host range of lysing $3 / 11$ strains suggesting a broader anti-bacterial spectrum of the purified phage enzyme.

\subsubsection{LysVPMS1}

LysVPMS1 was obtained from V. parahaemolyticus bacteriophage VPMS1. The host used to propagate the phage was isolated from shrimp farms in northwestern Mexico during an acute hepatopancreatic necrosis disease (AHPND) outbreak in 2014. This endolysin is the first reported phage lytic enzyme against $V$. parahaemolyticus AHPND strains. LysVPMS1 showed lytic activity against 17 AHPND strains and 5 non- AHPND strains. The highest rate of muralytic activity was observed in case of $V$. parahaemolyticus ATCC-17802 strain (96\%). This information is quite significant in terms of the ability of purified LysVPMS1 to lyse strains from different origins with different degrees of pathogenicity. Moreover, this endolysin has the unique ability to lyse the cell wall of other Vibrio species specifically $V$. alginolyticus, $V$. harveyi and $V$. campbellii. More information on biochemical and bactericidal properties of the LysVPMS1 endolysin is presently unavailable [62].

\subsubsection{LysVPp1}

VPp1 is a double-stranded DNA phage capable of infecting $V$. parahaemolyticus strains belonging to Myoviridae family. Its genome consists of $50,431 \mathrm{bp}$ with a $\mathrm{G}+\mathrm{C}$ content of $41.35 \%$. The ability of VPp1 to reduce bacterial load during depurination in oysters was reported back in 2014 [36]. Recently, endolysin (LysVPp1) derived from VPp1 was purified and assessed for its anti-bacterial activities. LysVPp1 is a soluble lytic transglycosylase related to hen egg white lysozyme with a molecular weight of $\sim 44 \mathrm{kDa}$ and yield of $1 \mathrm{mg} / \mathrm{mL}$. Peptidoglycan binding domain was not reported in LysVPp1.No holins/antiholin were also annotated in the phage genome. The antibacterial spectrum of the lysin was evaluated via two methods-(1) gel diffusion assay and (2) turbidity reduction assay. In gel diffusion assay, $V$. parahaemolyticus ATCC 17802 was used as the substrate. The hydrolase activity was determined by color changes around the holes in gels $(0.01 \%$ potassium hydroxide $+0.1 \%$ methylene blue) containing peptidoglycan. Gel holes treated with LysVPp1 showed a light blue color resulting from the hydrolysis of peptidoglycan, thereby validating the hydrolytic activity of recombinant enzyme. In addition, the turbidity of EDTA-pretreated $V$. parahaemolyticus cells was reduced by $0.4 \log$ after 5 min of incubation. The lytic spectrum assay of parent strain VPp1 lysed only V. parahaemolyticus 
isolates whereas the recombinant lysin LysVPp1 could hydrolyze 9 of 12 Vibrio strains tested, which included closely related Vibrio strains such as V. parahaemolyticus, V. campbellii, and V. azureus [61].

\section{2. cwlQ- First Recombinant Endolysin with Holin Assistance}

Vp670 is lytic phage of Podoviridae family capable of infecting $V$. alginolyticus strains. This is the first report of a $V$. alginolyticus phage whose lysis cassette was annotated, cloned and expressed. The genome size of Vp670 is 43,121 bp which codes for $49 \mathrm{ORFs}$ and contains a lysis module, composed of two components- holA (holin) and cwlQ (endolysin). cwlQ is a relatively small protein(15-20 kDa) belonging to hydrolase-2 domain superfamily (Pfam 07486). TM pred analysis showed holA has a transmembrane helix with a hydrophilic C-terminal region inside the cytoplasmic membrane. Clones were expressed in E. coli (LPN028 and LPN030) and V. alginolyticus (LPN041 and LPN043) strains and these cells were able to survive under L-arabinose induction conditions. The clone expression was further studied by TEM analysis. Clones with holA and $c w l Q$ had their OM layer disrupted and their cellular contents released from channels in the cell membrane. Cells without expressed genes had intact cellular structures with no morphological difference. Coexpression of both genes has resulted in severe cell damage compared to the expression of holA alone in the cells [57].

The therapeutic potential of the above reported endolysins been investigated in neither in vitro nor in vivo models.

\section{Challenges of Endolysin Engineering and Delivery}

There are numerous reports supporting the antibacterial activity of endolysins in vivo, but only a few of them have been proven by human clinical trials. There are numerous reports supporting the antibacterial activity of endolysins in vivo, but little information has been published on human clinical trials. SAL200 is the first endolysin based therapeutic formulation with a recombinant form of phage endolysin SAL-1 (rSAL-1) derived from the bacteriophage SAP-1, as its active pharmaceutical ingredient. SAP-1 infects Staphylococci, including MRSA and vancomycin-resistant S. aureus (VRSA) strains [66,67]. The first in-human phase 1 study of SAL200 provided preliminary information on safety, tolerability, pharmacokinetics, and pharmacodynamics of the product upon intravenous injection among healthy adults [68]. No serious adverse effects were observed in volunteers except mild and temporarily observed effects such as fatigue, headaches and myalgia. Similarly Staphefekt SA.100, a recombinant phage endolysin formulated ointment against infections caused by MRSA strains is available in a cetomacrogol-based cream/gel as over-the-counter treatment in Europe since 2017 [69].

Many challenges need to be addressed and overcome to deliver engineered chimeric endolysins. Lysins are non-replicating proteinaeous molecules with short half-life in systemic circulation [21,70]. They also elicit immunological response when applied systemically leading to catalytic loss of the enzyme [65]. Endolysins can be used in combination with other anti-bacterials, as they have been proven to act synergistically with antibiotics [71]. Currently, studies on lysin dosage are underdeveloped. Safe and successful therapeutic application of endolysin requires detailed information on bioavailability, immunogenicity and lysin synergy. More human clinical trials are anticipated to investigate phage endolysin treatments to combat several human pathogens. This is extremely important due to the substantial increase of multi-drug resistant pathogens and the steady decline in the discovery of new classes of antibiotics.

\section{Conclusions}

The extensive use of antibiotics has resulted in the emergence of multidrug resistant 'superbugs' worldwide. Bacteriophage encoded lytic enzymes 'endolysins' have enormous anti-microbial potential to fight against food borne pathogens in this multi-drug-resistance era. Promising results have encouraged active phage researchers to apply phage enzymes in various fields, such as food safety, pathogen detection, surface decontamination and nanotechnology. All reported endolysins showed a broad activity spectrum for the genus Vibrio. Research on Vibrio phage-encoded lytic enzymes has 
intensified since 2016. Lysqdvp001 and its homologues are highly divergent enzymes which are capable of superior lytic and antibacterial activity compared to their parent phages. Several attributes, such as high catalytic activity, modular structure and dual catalytic domains, support the robust development of them as novel alternatives to conventional antibiotic therapy. As the most abundant biological entity on earth, Bacteriophages' lytic proteins are also considered structurally and functionally divergent. Bio-informatic and proteomic studies will allow researchers to expand endolysins as a powerful tool with diverse applications.

Author Contributions: This review paper is a part of the Ph.D. work of author N.M. All the authors contributed to the writing and the proofreading of all versions of this article.

Funding: This research received no external funding.

Acknowledgments: The authors acknowledge Department of Biotechnology, Cochin University of Science and Technology for providing all facilities for research.

Conflicts of Interest: The authors declare no conflict of interest.

\section{References}

1. Barbarossa, V.; Kucisec-Tepes, N.; Aldova, E.; Matek, D.; Stipoljev, F. Ilizarov technique in the treatment of chronic osteomyelitis caused by Vibrio alginolyticus. Croat. Med. J. 2002, 43, 346-349. [PubMed]

2. Feingold, M.H.; Kumar, M.L. Otitis media associated with Vibrio alginolyticus in a child with pressure equalizing tubes. Pediatr. Infect. Dis. J. 2004, 23, 475-476. [CrossRef] [PubMed]

3. Li, X.C.; Xiang, Z.Y.; Xu, X.M.; Yan, W.H.; Ma, J.M. Endophthalmitis caused by Vibrio alginolyticus. J. Clin. Microbiol. 2009, 47, 3379-3381. [CrossRef] [PubMed]

4. $\mathrm{Xu}, \mathrm{X}$; Cheng, J.; Wu, Q.; Zhang, J.; Xie, T. Prevalence, characterization, and antibiotic susceptibility of Vibrio parahaemolyticus isolated from retail aquatic products in North China. BMC Microbiol. 2016, 16, 32. [CrossRef] [PubMed]

5. Elmahdi, S.; DaSilva, L.V.; Parveen, S. Antibiotic resistance of Vibrio parahaemolyticus and Vibrio vulnificus in various countries: A review. Food Microbiol. 2016, 57, 128-134. [CrossRef]

6. Romero, J.; Feijoó, C.G.; Navarrete, P. Antibiotics in aquaculture-use, abuse and alternatives. In Health and Environment in Aquaculture; InTechOpen: London, UK, 2012.

7. Daniels, N.A.; Shafaie, A. A Review of Pathogenic Vibrio Infections for Clinicians. Infect. Med. 2000, 17, 665-685.

8. CDC. Cholera and Other Vibrio Illness Surveillance (COVIS). 2016. Available online: https:/ / www.cdc.gov/ vibrio/surveillance.html (accessed on 28 January 2019).

9. Kumar, S.; Singh, B. Ran Overview of Mechanisms and Emergence of Antimicrobials Drug Resistance. 2013. Available online: http:/ / krishi.icar.gov.in/jspui/handle/123456789/11178 (accessed on 5 February 2019).

10. Munita, J.M.; Arias, C.A. Mechanisms of antibiotic resistance. Microbiol. Spectr. 2016, 4. [CrossRef]

11. Miller, S.I. Antibiotic resistance and regulation of the gram-negative bacterial outer membrane barrier by host innate immune molecules. mBio 2016, 7, e01541-16. [CrossRef]

12. Partridge, S.R. Analysis of antibiotic resistance regions in Gram-negative bacteria. FEMS Microbiol. Rev. 2011, 35, 820-855. [CrossRef] [PubMed]

13. Chen, Y.; Chen, X.; Yu, F.; Wu, M.; Wang, R.; Zheng, S.; Zhu, J. Serology, virulence, antimicrobial susceptibility and molecular characteristics of clinical Vibrio parahaemolyticus strains circulating in southeastern China from 2009 to 2013. Clin. Microbiol. Infect. 2016, 22, 258.e9-258.e16. [CrossRef]

14. Hooper, D.C. Mechanisms of action of antimicrobials: Focus on fluoroquinolones. Clin. Infect. Dis. 2001, 32 (Suppl. 1), S9-S15. [CrossRef]

15. Kitaoka, M.; Miyata, S.T.; Unterweger, D.; Pukatzki, S. Antibiotic resistance mechanisms of Vibrio cholerae. J. Med. Microbiol. 2011, 60, 397-407. [CrossRef] [PubMed]

16. Wong, H.C.; Wang, T.Y.; Yang, C.W.; Tang, C.T.; Ying, C.; Wang, C.H.; Chang, W.H. Characterization of a lytic vibriophage VP06 of Vibrio parahaemolyticus. Res. Microbiol. 2018. [CrossRef] [PubMed]

17. Morris, J.G., Jr.; Tenney, J. Antibiotic therapy for Vibrio vulnificus infection. JAMA 1985, 253, 1121-1122. [CrossRef] [PubMed] 
18. Kitiyodom, S.; Khemtong, S.; Wongtavatchai, J.; Chuanchuen, R. Characterization of antibiotic resistance in Vibrio spp. isolated from farmed marine shrimps (Penaeus monodon). FEMS Microbiol. Ecol. 2010, 72, $219-227$. [CrossRef] [PubMed]

19. Ye, L.; Li, R.; Lin, D.; Zhou, Y.; Fu, A.; Ding, Q.; Chen, S. Characterization of an IncA/C multidrug resistance plasmid in Vibrio alginolyticus. Antimicrob. Agents Chemother. 2016, 60, 3232-3235. [CrossRef] [PubMed]

20. Ralston, E.P.; Kite-Powell, H.; Beet, A. An estimate of the cost of acute health effects from food-and water-borne marine pathogens and toxins in the USA. J. Water Health 2009, 9, 680-694. [CrossRef]

21. O'Flaherty, S.; Ross, R.P.; Coffey, A. Bacteriophage and their lysins for elimination of infectious bacteria. FEMS Microbiol. Rev. 2009, 33, 801-819. [CrossRef]

22. Young, R. Phage lysis: Do we have the whole story yet? Curr. Opin. Microbiol. 2013, 16, 790-797. [CrossRef]

23. Berry, J.D.; Rajaure, M.; Pang, T.; Young, R. The spanin complex is essential for lambda lysis. J. Bacteriol. 2012, 194, 5667-5674. [CrossRef]

24. Young, R.; Way, S.; Yin, J.; Syvanen, M. Transposition mutagenesis of bacteriophage lambda: A new gene affecting cell lysis. J. Mol. Biol. 1979, 132, 307-322. [CrossRef]

25. Krupovič, M.; Cvirkaitè-Krupovič, V.; Bamford, D.H. Identification and functional analysis of the Rz/Rz1-like accessory lysis genes in the membrane-containing bacteriophage PRD1. Mol. Microbiol. 2008, 68, 492-503. [CrossRef] [PubMed]

26. Berry, J.; Savva, C.; Holzenburg, A.; Young, R. The lambda spanin components Rz and Rz1 undergo tertiary and quaternary rearrangements upon complex formation. Protein Sci. 2010, 19, 1967-1977. [CrossRef] [PubMed]

27. Nelson, D.; Loomis, L.; Fischetti, V.A. Prevention and elimination of upper respiratory colonization of mice by group A streptococci by using a bacteriophage lytic enzyme. Proc. Natl. Acad. Sci. USA 2001, 98, 4107-4112. [CrossRef] [PubMed]

28. Donovan, D.M.; Dong, S.; Garrett, W.; Rousseau, G.M.; Moineau, S.; Pritchard, D.G. Peptidoglycan hydrolase fusions maintain their parental specificities. Appl. Environ. Microbol. 2006, 72, 2988-2996. [CrossRef] [PubMed]

29. Beveridge, T.J. Structures of gram-negative cell walls and their derived membrane vesicles. J. Bacteriol. 1999, 181, 4725-4733.

30. Larpin, Y.; Oechslin, F.; Moreillon, P.; Resch, G.; Entenza, J.M.; Mancini, S. In vitro characterization of PlyE146, a novel phage lysin that targets Gram-negative bacteria. PLoS ONE 2018, 13, e0192507. [CrossRef] [PubMed]

31. Low, L.Y.; Yang, C.; Perego, M.; Osterman, A.; Liddington, R. Role of net charge on catalytic domain and influence of cell wall binding domain on bactericidal activity, specificity, and host range of phage lysins. J. Biol. Chem. 2011, 286, 34391-34403. [CrossRef]

32. Chen, H.-M.; Li, Y.; Panda, T.; Buehler, F.U.; Ford, C.; Reilly, P.J. Effect of replacing helical glycine residues with alanines on reversible and irreversible stability and production of Aspergillus awamori glucoamylase. Protein Eng. 1996, 9, 499-505. [CrossRef]

33. Briers, Y.; Lavigne, R.; Volckaert, G.; Hertveldt, K. A standardized approach for accurate quantification of murein hydrolase activity in high-throughput assays. J. Biochem. Biophys. Methods 2007, 70, 531-533. [CrossRef]

34. Sanz-Gaitero, M.; Keary, R.; Garcia-Doval, C.; Coffey, A.; van Raaij, M.J. Crystallization of the CHAP domain of the endolysin from Staphylococcus aureus bacteriophage K. Acta Crystallogr. Sect. F Struct. Biol. Cryst. Commun. 2013, 69, 1393-1396. [CrossRef] [PubMed]

35. Becker, S.C.; Swift, S.; Korobova, O.; Schischkova, N.; Kopylov, P.; Donovan, D.M.; Abaev, I. Lytic activity of the staphylolytic Twort phage endolysin CHAP domain is enhanced by the SH3b cell wall binding domain. FEMS Microbiol. Lett. 2015, 362, 1. [CrossRef] [PubMed]

36. Walmagh, M.; Boczkowska, B.; Grymonprez, B.; Briers, Y.; Drulis-Kawa, Z.; Lavigne, R. Characterization of five novel endolysins from Gram-negative infecting bacteriophages. Appl. Microbiol. Biotechnol. 2013, 97, 4369-4375. [CrossRef]

37. Oliveira, H.; Melo, L.D.; Santos, S.B.; Nóbrega, F.L.; Ferreira, E.C.; Cerca, N.; Azeredo, J.; Kluskens, L.D. Molecular aspects and comparative genomics of bacteriophage endolysins. J. Virol. 2013, 87, 4558-4570. [CrossRef] [PubMed]

38. Yang, H.; Yu, J.; Wei, H. Engineered bacteriophage lysins as novel anti-infectives. Front. Microbiol. 2014, 5, 542. [CrossRef] 
39. Idelevich, E.A.; von Eiff, C.; Friedrich, A.W.; Iannelli, D.; Xia, G.; Peters, G.; Peschel, A.; Wanninger, I.; Becker, K. In vitro activity against Staphylococcus aureus of a novel antimicrobial agent, PRF-119, a recombinant chimeric bacteriophage endolysin. Antimicrob. Agents Chemother. 2011, 55, 4416-4419. [CrossRef] [PubMed]

40. Fernandes, S.; Proença, D.; Cantante, C.; Silva, F.A.; Leandro, C.; Lourenço, S.; Milheiriço, C.; de Lencastre, H.; Cavaco-Silva, P.; Pimentel, M.; et al. Novel chimerical endolysins with broad antimicrobial activity against methicillin-resistant Staphylococcus aureus. Microb. Drug Resist. 2012, 18, 333-343. [CrossRef]

41. Mao, J.; Schmelcher, M.; Harty, W.J.; Foster-Frey, J.; Donovan, D.M. Chimeric Ply187 endolysin kills Staphylococcus aureus more effectively than the parental enzyme. FEMS Microbiol. Lett. 2013, 1, 30-36. [CrossRef]

42. Dong, Q.; Wang, J.; Yang, H.; Wei, C.; Yu, J.; Zhang, Y.; Huang, Y.; Zhang, X.E.; Wei, H. Construction of a chimeric lysin Ply187N-V12C with extended lytic activity against staphylococci and streptococci. Microb. Biotechnol. 2014. [CrossRef]

43. Yang, H.; Zhang, Y.; Yu, J.; Huang, Y.; Zhang, X.E.; Wei, H. Novel chimeric lysin with high-level antimicrobial activity against methicillin-resistant Staphylococcus aureus in vitro and in vivo. Antimicrob. Agents Chemother. 2014, 58, 536-542. [CrossRef]

44. Yang, H.; Zhang, H.; Wang, J.; Yu, J.; Wei, H. A novel chimeric lysin with robust antibacterial activity against planktonic and biofilm methicillin-resistant Staphylococcus aureus. Sci. Rep. 2017, 7, 40182. [CrossRef]

45. Briers, Y.; Walmagh, M.; Grymonprez, B.; Biebl, M.; Pirnay, J.P.; Defraine, V.; Michiels, J.; Cenens, W.; Aertsen, A.; Miller, S.; et al. Art-175 is a highly efficient antibacterial against multidrug-resistant strains and persisters of Pseudomonas aeruginosa. Antimicrob. Agents Chemother. 2014, 58, 3774-3784. [CrossRef]

46. Lukacik, P.; Barnard, T.J.; Keller, P.W.; Chaturvedi, K.S.; Seddiki, N.; Fairman, J.W.; Noinaj, N.; Kirby, T.L.; Henderson, J.P.; Steven, A.C.; et al. Structural engineering of a phage lysin that targets gram-negative pathogens. Proc. Natl. Acad. Sci. USA 2012, 109, 9857-9862. [CrossRef] [PubMed]

47. Zampara, A.; Sørensen, M.C.; Grimon, D.; Antenucci, F.; Briers, Y.; Brøndsted, L. Innolysins: A novel approach to engineer endolysins to kill Gram-negative bacteria. BioRxiv 2018, 408948. [CrossRef]

48. Crothers-Stomps, C.; Høj, L.; Bourne, D.G.; Hall, M.R.; Owens, L. Isolation of lytic bacteriophage againstVibrio harveyi. J. Appl. Microbiol. 2010, 108, 1744-1750. [CrossRef] [PubMed]

49. Rong, R.; Lin, H.; Wang, J.; Khan, M.N.; Li, M. Reductions of Vibrio parahaemolyticus in oysters after bacteriophage application during depuration. Aquaculture 2014, 418, 171-176. [CrossRef]

50. Zhang, J.; Cao, Z.; Xu, Y.; Li, X.; Li, H.; Wu, F.; Jin, L. Complete genomic sequence of the Vibrio alginolyticus lytic bacteriophage PVA1. Arch. Virol. 2014, 159, 3447-3451. [CrossRef] [PubMed]

51. Li, Z.; Li, X.; Zhang, J.; Wang, X.; Wang, L.; Cao, Z.; Xu, Y. Use of phages to control Vibrio splendidus infection in the juvenile sea cucumber Apostichopus japonicus. Fish Shellfish Immunol. 2016, 54, 302-311. [CrossRef] [PubMed]

52. Kim, S.G.; Giri, S.S.; Jun, J.W.; Yun, S.; Kim, H.J.; Kim, S.W.; Kang, J.W.; Han, S.J.; Jeong, D.; Park, S.C. Concentration-dependent reduction of planktonic-and biofilm-state Vibrio alginolyticus by the bacteriophage pVa-21. BioRxiv 2018, 322933. [CrossRef]

53. Skliros, D.; Kalatzis, P.G.; Katharios, P.; Flemetakis, E. Comparative functional genomic analysis of two vibrio phages reveals complex metabolic interactions with the host cell. Front. Microbiol. 2016, 7, 1807. [CrossRef]

54. Lal, T.M.; Sano, M.; Hatai, K.; Ransangan, J. Complete genome sequence of a giant Vibrio phage ValKK3infectingVibrioalginolyticus. Genomicsdata 2016, 8, 37. [CrossRef]

55. Skliros, D.; Kalatzis, P.G.; Flemetakis, E. Biotechnology, Agricultural University of Athens, Iera Odos, Athens, Attika 11855, Greece Comparative genomics of small Myoviridae Vibriophages (GenBank accession number: MG640035.1). 2017.

56. Kokkari, C.; Sarropoulou, E.; Bastias, R.; Mandalakis, M.; Katharios, P. Isolation and characterization of a novel bacteriophage infecting Vibrio alginolyticus. Arch. Microbiol. 2018, 200, 707-718. [CrossRef] [PubMed]

57. Luo, P.; Yun, L.; Li, Y.; Tian, Y.; Liu, Q.; Huang, W.; Hu, C. Complete genomic sequence of the Vibrio alginolyticus bacteriophage Vp670 and characterization of the lysis-related genes, cwlQ and holA. BMC Genom. 2018, 19, 741. [CrossRef] [PubMed]

58. Li, F.; Xing, S.; Fu, K.; Zhao, S.; Liu, J.; Tong, Y.; Zhou, L. Genomic and biological characterization of the Vibrio alginolyticus-infecting "Podoviridae" bacteriophage, vB_ValP_IME271. Virus Genes 2019, 1-9. [CrossRef] 
59. Wang, W.; Li, M.; Lin, H.; Wang, J.; Mao, X. The Vibrio parahaemolyticus-infecting bacteriophage qdvp001: Genome sequence and endolysin with a modular structure. Arch. Virol. 2016, 161, 2645-2652. [CrossRef] [PubMed]

60. Wong, M.H.Y.; Liu, M.; Wan, H.Y.; Chen, S. Characterization of Extended Spectrum $\beta$-lactamase Producing Vibrio parahaemolyticus. Antimicrob. Agents Chemother. 2012, 56, 4026-4028. [CrossRef] [PubMed]

61. Li, M.; Jin, Y.; Lin, H.; Wang, J.; Jiang, X. Complete Genome of a Novel Lytic Vibrio parahaemolyticus Phage VPp1 and Characterization of Its Endolysin for Antibacterial Activities. J. Food Prot. 2018, 81, 1117-1125. [CrossRef] [PubMed]

62. Zermeño-Cervantes, L.A.; Makarov, R.; Lomelí-Ortega, C.O.; Martínez-Díaz, S.F.; Cardona-Félix, C.S. Recombinant Lys VPMS 1 as an endolysin with broad lytic activity against Vibrio parahaemolyticus strains associated to acute hepatopancreatic necrosis disease. Aquac. Res. 2018, 49, 1723-1726. [CrossRef]

63. Lal, T.M.; Ransangan, J. Complete genome sequence of VpKK5, a novel Vibrio parahaemolyticus lytic siphophage. Genome Announc. 2015, 3. [CrossRef]

64. Midorikawa, Y.; Sano, M. okyo University of Marine Science and Technology; Konan 4-5-7, Minato-ku, Tokyo, Japan. Complete Genome Sequence of Vibrio parahaemolyticus Bacteriophage pTD1 (GenBank accession number: AP017972.1). 2017.

65. Fischetti, V.A. Bacteriophage lysins as effective antibacterials. Curr. Opin. Microbiol. 2008, 11, $393-400$. [CrossRef]

66. Jun, S.Y.; Jung, G.M.; Son, J.S.; Yoon, S.J.; Choi, Y.J.; Kang, S.H. Comparison of the antibacterial properties of phage endolysins SAL-1 and LysK. Antimicrob. Agents Chemother. 2011, 55, 1764-1767. [CrossRef]

67. Jun, S.Y.; Jung, G.M.; Yoon, S.J.; Oh, M.D.; Choi, Y.J.; Lee, W.J.; Kong, J.C.; Seol, J.G.; Kang, S.H. Antibacterial properties of a pre-formulated recombinant phage endolysin, SAL-1. Int. J. Antimicrob. Agents 2013, 41, 156-161. [CrossRef] [PubMed]

68. Jun, S.Y.; Jang, I.J.; Yoon, S.; Jang, K.; Yu, K.S.; Cho, J.Y.; Kang, S.H. Pharmacokinetics and tolerance of the phage endolysin-based candidate drug SAL200 after a single intravenous administration among healthy volunteers. Antimicrob. Agents Chemother. 2017, 61, e02629-16. [CrossRef]

69. Totté, J.E.; van Doorn, M.B.; Pasmans, S.G. Successful treatment of chronic Staphylococcus aureus-related dermatoses with the topical endolysin Staphefekt SA. 100: A report of 3 cases. Case Rep. Dermatol. 2017, 9 , 19-25. [CrossRef]

70. Loeffler, J.M.; Djurkovic, S.; Fischetti, V.A. Phage lytic enzyme Cpl-1 as a novel antimicrobial for pneumococcal bacteremia. Infect. Immun. 2003, 71, 6199-6204. [CrossRef] [PubMed]

71. Barrera-Rivas, C.I.; Valle-Hurtado, N.A.; González-Lugo, G.M.; Baizabal-Aguirre, V.M.; Bravo-Patiño, A.; Cajero-Juárez, M.; Valdez-Alarcón, J.J. Bacteriophage Therapy: An Alternative for the Treatment of Staphylococcus aureus Infections in Animals and Animal Models; Frontiers in Staphylococcus aureus; InTechOpen: London, UK, 2017. [CrossRef]

(C) 2019 by the authors. Licensee MDPI, Basel, Switzerland. This article is an open access article distributed under the terms and conditions of the Creative Commons Attribution (CC BY) license (http:/ / creativecommons.org/licenses/by/4.0/). 